\section{¿QUÉ ES CULTURA EN LA "ECONOMÍA DE LA CULTURA"? DEFINIENDO LA CULTURA PARA CREAR MODELOS MENSURABLES EN ECONOMÍA CULTURAL}

\author{
Aníbal Monasterio Astobiza \\ Universidad del País Vasco \\ anibal.monasterio@ehu.eus \\ http://orcid.org/0000-0003-1399-5388
}

\section{WHAT IS CULTURE IN "CULTURAL ECONOMY»? DEFINING CULTURE TO CREATE MEASURABLE MODELS IN CULTURAL ECONOMY}

Cómo citar este artículo/Citation: Monasterio Astobiza, A. (2017). ¿Qué es cultura en la "economía de la cultura»? Definiendo la cultura para crear modelos mensurables en economía cultural. Arbor, 193 (783): a376. doi: http://dx.doi. org/10.3989/arbor.2017.783n1007

Recibido: 16 junio 2015. Aceptado: 17 diciembre 2015.

RESUMEN: El concepto de cultura es bastante vago y ambiguo para los objetivos formales de la economía. En este escrito se pretende definir y acotar mejor el espacio semántico de la idea de cultura para ayudar a crear explicaciones económicas basadas en la cultura dirigidas a medir el retorno e impacto económico y social de toda actividad o creencia asociada a la cultura. Por cultura, de acuerdo con la definición evolutiva canónica, se entiende cualquier tipo de comportamiento ritualizado o convertido en significativo para un grupo de individuos que permanece, más o menos, constante y es trasmitido intergeneracionalmente a través del tiempo. Toda institución económica se basa, implícita o explícitamente, en una visión de cómo funcionamos los seres humanos, la cultura es imprescindible para entendernos, por ello, es necesario describir correctamente qué es lo que se entiende por cultura. En este escrito hacemos una revisión de la literatura en antropología y psicología evolucionista en torno al concepto de cultura para advertir que una modelización económica de la cultura ignora aspectos intangibles de los beneficios de la cultura y que por tanto la economía se muestra incapaz de medir algunos ítems culturales en la sociedad de consumo digital.

PALABRAS CLAVE: Cultura; evolución de la cultura; economía de la cultura; cooperación; status; psicología.
Copyright: (c) 2017 CSIC. Este es un artículo de acceso abierto distribuido bajo los términos de la licencia Creative Commons Attribution (CC BY) España 3.0.

ABSTRACT: The idea of culture is somewhat vague and ambiguous for the formal goals of economics. The aim of this paper is to define the notion of culture better so as to help build economic explanations based on culture and therefore to measure its impact in every activity or beliefs associated with culture. To define culture according to the canonical evolutionary definition, it is any kind of ritualised behaviour that becomes meaningful for a group and that remains more or less constant and is transmitted down through the generations. Economic institutions are founded, implicitly or explicitly, on a worldview of how humans function; culture is an essential part of understanding us as humans, making it necessary to describe what we understand by culture correctly. In this paper we review the literature on evolutionary anthropology and psychology dealing with the concept of culture to warn that economic modelling ignores intangible benefits of culture rendering economics unable to measure certain cultural items in the digital consumer society.

KEYWORDS: Culture; evolution of culture; cultural economics; cooperation; status; psychology. 


\section{INTRODUCCIÓN: BREVÍSIMA HISTORIA DE LA ECONOMÍA CULTURAL}

La economía cultural o economía de la cultura es una rama de la economía que investiga explicaciones o hipótesis culturales como determinantes de retorno o impacto económico. Con el uso de técnicas analíticas y herramientas empíricas traídas de la matemática se identifican diferencias sistemáticas de la influencia que ejerce la cultura en el desarrollo económico de las regiones, territorios y países. En este sentido, la economía cultural o economía de la cultura (Baumol y Bowen 1965; Baumol y Bowen 1966) es una detallada y específica investigación de las condiciones económicas de la cultura o las artes (literatura, música, cine...).

La economía cultural es un desarrollo reciente del discurso económico. Hasta hace bien poco los economistas no tenían por objeto de estudio la cultura porque la consideraban demasiado ambigua, abstracta y muy difícil de medir cuantitativamente. Sin embargo, distintos autores de diferentes épocas empiezan a vislumbrar el poder de las fuerzas culturales (creencias, valores, preferencias...) en el desarrollo económico de las sociedades. Algunos de estos autores son Karl Marx, Max Weber, John M. Keynes o Thorstein Veblen, por citar unos pocos. Pero no todos estos autores pioneros en la consideración de la cultura como factor económico tienen clara la relación o dirección causal entre la economía y la cultura. Algunos de ellos consideran que la economía crea la cultura, mientras que otros creen que la cultura crea la economía. No obstante, en la economía mainstream la cultura será vista como efecto más que como causa de la economía y siempre con un papel más bien secundario.

Para Karl Marx la cultura, el orden social, está determinado por los medios de producción de la técnica. Para él el molino de viento crea la sociedad feudal y la máquina de vapor el capitalismo. Max Weber revierte este orden causal en su Ética protestante $y$ el espíritu del capitalismo y ve en la fuerza de la religión (creencias) la espuela que mueve el cambio de paradigma económico. El trabajo duro, la austeridad, pero también la acumulación de capital resultan fomentados por un vuelco en dos dogmas religiosos básicos: la amisibilidad (del latín amittere que significa que se puede "perder") de la gracia y la predestinación de las almas. Si tu alma no tiene garantizado el perdón eterno y tú no tienes por qué ser elegido de antemano para ir al reino de los cielos, entonces tus acciones en vida son las que serán juzgadas. Si a esto sumamos que la acumulación de capital ya no será condenada moralmente como usura, el origen del capitalismo emergerá como consecuencia de las creencias (cultura).

John M. Keynes y sus obras canónicas, entre ellas The General Theory of Employment, Interest and Money, representa una renuncia a la ortodoxia del mercado de la economía clásica y la teoría racional de la utilidad. A pesar de la riqueza del archivo de Keynes los historiadores y economistas solo se han centrado en su opus magnum (La Teoría General). Pero la antología entera de sus escritos con artículos, emisiones radiofónicas y correspondencia epistolar publicada en 1981 por la Royal Economic Society muestra su interés por las artes como una buena analogía del mercado que más allá de comportarse racionalmente es intrínsecamente irracional. La irracionalidad es una característica definitoria de la sociedad civil, y por ende de los mercados. Los "espíritus animales" o, dicho de otro modo, la psicología instintiva de los actores económicos es el verdadero modus operandi de la economía. La psicología instintiva se manifiesta en la creatividad y la creatividad es propia de las artes. En su ensayo Arte y Estado Keynes crítica al gobierno británico por errar en "mantener la grandeza y dignidad del Estado". Para Keynes son las artes las que hacen de un estado lo que es porque las artes crean un "orgullo cívico y un sentido de unidad social" (Moggridge, 2005, p. 345). Keynes critica que el estado no interfiera en los asuntos sociales.

Por su parte, Thorstein Veblen introduce en su obra The Theory of Leisure Class la noción de consumo u ocio conspicuo. Para Veblen el comportamiento de la gente se ve modificado por la riqueza. La gente que posee riqueza o está a la búsqueda de ella solo busca el estatus o eminencia que el dinero otorga. Esto causa una lucha por el dinero que una vez que se tiene crea una necesidad de apariencia social: ostentar. Esta apariencia social mueve a las personas a emular o sobrepasar la riqueza de otros. $Y$ esto se hace a través del consumo u ocio conspicuo.

El consumo conspicuo no es un consumo de subsistencia. Si así fuera habría un punto en el que el incentivo de acumular bienes cesaría, pero este no es el caso. Consumir conspicuamente es valioso en sí mismo. Lo que se está señalando cuando se consume conspicuamente es que se tiene la riqueza para consumir bienes ostentosos (en muchos casos superfluos y fruto del esnobismo) y que se forma parte de una clase ociosa que no necesita trabajar para consumir dichos bienes y, a su vez, se señala que el propio estatus social es alto. Los productos de la cultura, las artes, son para la clase ociosa el principal medio o forma de consumo conspicuo. 
Mientras que Marx relega a la cultura a un segundo plano, Weber es el primero en reconocer cómo ciertos mecanismos de la cultura (creencias) influyen en la economía. Es de interés para este escrito examinar los extremos descritos por esta tétrada de autores: Keynes (cultura pública) y Veblen (cultura privada), Marx (economía crea cultura) y Weber (cultura crea economía) en tanto en cuanto fomentar uno u otro tipo de economía cultural tendrá una diferenciada influencia en la economía común y general. Una de las conclusiones más perennes de la economía de la cultura desde el clásico estudio de Baumol y Bowen (1965), es la gran cantidad de costos adicionales, "enfermedad de los costos", que las artes en general producen, de ahí que el estado tenga que subsidiarlas. Esta visión de la economía cultural sería considerada más keynesiana-weberiana frente a un enfoque más privado y coleccionista, más propio de una concepción Veblen-Marxiana, donde es la riqueza la que crea cultura.

En las siguientes páginas se definirá la noción de cultura desde la aplicación de la teoría darwiniana aplicada a la cultura para establecer apropiadamente qué es la cultura y, finalmente, se reconocerá que una modelización estrictamente económica puede ignorar ciertos beneficios intangibles de la cultura.

\section{2. ¿QUÉ ES LA CULTURA?}

La cultura es una noción difícil de medir y estudiar a través de los métodos formales que han venido utilizando los economistas. Por dos razones principales:

1) una mala interpretación del término cultura y 2) como consecuencia de una definición equívoca de la idea de cultura, un mal entendimiento de los mecanismos culturales para medir su retorno o impacto económico.

Con respecto a la razón 1) la polisemia de la noción de cultura ha llevado a muchas confusiones. Uno puede referirse a la cultura de una empresa, a la cultura de una época histórica, a la cultura de una persona y hasta a la subcultura de un grupo de la sociedad. Todos estos usos de la noción de cultura guardan un aire de familia, pero al mismo tiempo tienen su propia idiosincrasia.

En un artículo seminal Alfred Kroeber y Clyde Kluckohn (1952), antropólogos culturales, recogieron más de 162 usos del término y noción de cultura. De entre todos estos significados distintos agruparon o encontraron tres amplias temáticas o categorías en las que se podían subsumir los distintos usos. Una primera te- mática aludía a los estados mentales o pensamientos que dotaban de sentido a la cultura. En esta primera temática se englobarían creencias, valores, preferencias que las personas tienen en relación a lo que las personas consideran qué es la cultura.

Una segunda temática de significados caracteriza la cultura material de los objetos y artefactos: las instrucciones necesarias para su creación. En esta segunda categoría se incluyen pronunciamientos, copias, imitaciones o aprendizaje social sobre cómo hacer un objeto o cómo proceder a la hora de realizar una práctica.

La tercera y última temática describe la cultura exclusivamente humana mediada por la facultad del lenguaje. Mientras que las dos temáticas anteriores de cultura pueden vislumbrarse o estar presentes en otras especies animales, principalmente los primates no-humanos, en los cuales experimentos con chimpancés muestran cómo hay aprendizaje social, elaboración de herramientas rudimentarias, comportamientos ex novo o en los nidos nupciales de las aves de la familia Ptilonorhynchidae (pájaros jardineros como el Capulinero) se puede atribuir un gusto y una representación estética, así como otros procesos culturales (Odling-Smee, Laland y Feldman, 2003), este grupo definicional de la idea de cultura es propia del ser humano. Comprende la arquitectura, la música, la pintura y otras artes donde el lenguaje como sistema de representación y comunicación simbólico es una condición necesaria para la trasmisión de información y creación de cultura.

A partir de estas tres amplias clases de temáticas que emergen de los múltiples significados de cultura, revisados por Kroeber y Kluckohn, se puede extraer una definición neutra y comprehensiva de la idea o noción de cultura. La cultura es: tradiciones de comportamientos.

Desde la perspectiva evolutiva la cultura es cualquier tipo de comportamiento ritualizado o convertido en significativo para un grupo de individuos que permanece, más o menos, constante y es trasmitido intergeneracionalmente a través del tiempo. Para entender cómo ciertos comportamientos y no otros son beneficiosos para el grupo, qué mecanismos están detrás de la trasmisión de la cultura, cómo ha evolucionado etc., es útil establecer una analogía con la evolución biológica y aplicar el marco teórico darwiniano.

Estableciendo esta analogía entre el mundo biológico y el mundo de las variaciones culturales se podrán conocer los mecanismos y causas subyacentes 
a la evolución cultural. Es la definición evolutiva de cultura, el por qué y el cómo de su origen, lo que nos interesará, independientemente de las dimensiones o niveles de análisis desde las que se puede estudiar la cultura (país, sociedad, organización o individuo).

Desde un punto de vista evolucionista, la cultura es una adaptación a nivel grupal que permite estudiar la diversidad de comportamientos de la misma forma que se puede estudiar la diversidad biológica (Wilson, 2013; Laland, 2017).

En biología una adaptación es todo rasgo o característica de un organismo que ha evolucionado por selección natural en virtud de que incrementa la aptitud darwiniana (número de genes que pasarán a la siguiente generación). Por esto el estudio de cualquier ser vivo dado ha de comenzar con la certeza de que se ha adaptado a su entorno, de otra forma no existiría. Las especies biológicas son adaptativas a nivel individual, es decir, son adaptativas porque causan a los individuos que las poseen su supervivencia y reproducción frente a otros individuos. Un ejemplo de adaptación a nivel individual es la potente musculatura del guepardo para correr más rápido que otros animales y así atrapar a las presas.

Sin embargo, hay otras especies que tienen adaptaciones a nivel grupal. Hay especies de insectos eusociales (comportamiento social extremo) como las abejas, hormigas y termitas cuyos rasgos (adaptaciones) han evolucionado en virtud de que causan un incremento de la aptitud darwiniana de la colonia frente a otra colonia, no en virtud de un incremento de la aptitud darwiniana de un individuo frente a otro individuo. Como resultado estas colonias se convierten en unidades altamente cooperativas, en superorganismos (Wilson, 2013, p. 105).

Esta misma forma de entender la evolución de las especies biológicas se aplica a la evolución de las culturas. Como en el caso de las adaptaciones biológicas estas se han de estudiar caso por caso y la lista es muy extensa, pero la adaptación de las culturas se debe tomar como algo dado porque de otra forma no existirían. Las culturas son comportamientos (tradiciones de comportamientos) que han evolucionado por el bien del grupo.

Las culturas son adaptaciones de los grupos a su entorno circundante. Pero ¿qué mecanismos han dado lugar a nuestra capacidad para la cultura? Si se tuvieran que enumerar los dos mecanismos más importantes que dan lugar a la emergencia de la cultura, estos son: la cooperación y las normas.
Con respecto a la razón 2) de una mala definición de cultura en el discurso económico tradicional se deriva un mal conocimiento de los mecanismos culturales (cooperación y normas) que dan lugar a los productos culturales y, por tanto, la imposibilidad de medir su impacto o retorno económico. ¿Cómo los mecanismos culturales se pueden modelizar económicamente?

Si se entiende que los mecanismos principales que hay detrás de la emergencia y evolución de la cultura son la cooperación y las normas, la teoría de juegos es una rama de la matemática ideal para describir cómo estrategias antagónicas de n-personas alcanzan un equilibrio donde no tiene por qué haber un resultado de suma-cero (un jugador gana y el otro pierde), sino un "win-win" (todos ganan). Más abajo indicaremos cómo se producen estas situaciones, pero antes de nada hay que mencionar a quién debemos este progreso en la descripción de las estrategias racionales en situaciones de conflicto. Fue Garrett Hardin, un ecólogo, el que en 1968 publicó un clásico artículo titulado "The Tragedy of the commons" donde se muestra el conflicto y la tensión entre los intereses egoístas y personales, por una parte, y los intereses colectivos, por otra parte.

La parábola de Hardin es como sigue. Un grupo de pastores comparten un gran pasto que puede alimentar un gran grupo de animales pero no a infinitos animales. Periódicamente cada pastor decide introducir un animal a su rebaño. ¿Qué ha de hacer un pastor racional? Añadiendo un animal el pastor consigue un buen beneficio cuando vende el animal en el mercado. Sin embargo, el costo de introducir un animal al pasto es compartido por todos los que usan el terreno de pasto. Por lo tanto, el pastor gana mucho y solo paga un poco por añadir un animal adicional a su rebaño. En consecuencia el pastor estará mejor servido si decide introducir un animal más indefinidamente hasta que el pasto esté disponible. Pero por supuesto cada pastor tiene el mismo tipo de incentivos. Si cada pastor actúa de acuerdo a su propio interés el pasto común se extinguirá y no quedará nada para nadie.

El dilema del prisionero (Axelrod y Hamilton, 1981), otro tipo de juego dentro de la teoría de juegos, vuelve a mostrar la tensión entre los intereses personales y los intereses colectivos. Lo que tienen en común todos estos juegos es que tratan sobre el problema de la cooperación. La cultura con sus normas institucionalizadas o tácitas e implícitas es una solución para resolver el problema de la cooperación. A veces la cooperación es posible y otras es difícil o imposible. Imaginemos que Juan y Pedro están en un bote en 
medio del océano y quieren alejarse de una tormenta. Si ambos dejan de lado su interés egoísta de salvarse por ellos mismos y cooperan remando conjuntamente para alejarse de la tormenta es posible que se salven.

Pero imaginemos que Juan y Pedro están en el mismo bote y este se está yendo a pique y solo queda un salvavidas que no pueden usar los dos. En el primer caso la cooperación es posible, y la mejor solución, y en el segundo caso es imposible. En este caso hipotético se puede tener en cuenta que hay instintos innatos que por deriva genética se han fijado en buena parte de la población. Una demostración es el juego del ultimátum repetido una y otra vez en distintas poblaciones de todo el mundo. Si la situación se diera dentro de un grupo amplio, donde hubiera emparejamientos de uno en uno, la opción de cooperar se daría en al menos el $40 \%$ dejando el mayor que sobreviviera el menor, dado que este último tiene más posibilidades de reproducción ${ }^{1}$.

La cooperación se vuelve interesante en los casos intermedios entre los extremos cuando los intereses no están opuestamente alineados. Procesos psicológicos como la confianza sirven para permitir la cooperación y buscar el equilibrio de intereses en situaciones específicas (King-Casas et al., 2005; Corgnet, Espín, Hernán González, Kujal y Rassenti, 2016).

La cultura son tradiciones de comportamientos, hábitos más o menos estables que se trasmiten de generación en generación a través del tiempo y que benefician al grupo. La cooperación y las normas contribuyen a la emergencia y evolución de la cultura y la confianza como proceso psicológico facilita la cooperación. Esto es la cultura.

Entonces, ¿qué es cultura en la economía de la cultura? Para entender lo que significa "cultura" en la expresión "economía de la cultura" tenemos que fijarnos en un proceso psicológico básico que permite la aparición de los dos mecanismos que hay detrás de la cultura que antes mencionábamos: la cooperación y las normas. Este proceso o estado psicológico básico es la confianza.

La confianza es el lubricante necesario para cualquier tipo de intercambio social o económico. La confianza reduce cualquier tipo de costo adicional que solo un contrato legal puede prever y solucionar, pero el imperio de la ley que todos damos por sentado en una sociedad democrática y libre es una invención reciente que no ha existido la mayor parte del tiempo en nuestra historia evolutiva. La confianza es la respuesta natural que ha permitido el acuerdo informal.
De hecho, sigue siendo la confianza la mayor parte de las veces la que permite todo intercambio entre las personas. Célebre es el pasaje del Libro 1, capítulo 2 de La riqueza de las naciones de Adam Smith:

"No es de la benevolencia del carnicero, cervecero o panadero de donde obtendremos nuestra cena, sino de su preocupación por sus propios intereses".

Aquí en este pasaje célebre el motor del intercambio es la búsqueda de la maximización racional del interés propio. Como una "mano invisible" el auto-interés parece conducir al bien común. Pero una lectura del intercambio como auto-interés racional, ejemplo de un paradigma de economía de libre mercado, es seductivamente engañosa y hasta sofista; porque se olvida de reconocer la existencia de actividad económica basada en la confianza ${ }^{2}$. En este modelo el comprador y el vendedor no ven sus intereses basándose en un intercambio comercial auto-interesado, sino en la creación de valor mutuo.

Se puede definir la confianza como el estado psicológico que contiene la intención de aceptar vulnerabilidad basándose en las expectativas positivas de las intenciones o comportamiento de otro (Rousseau, Sitkin, Burt y Camerer, 1998). Definida así, la confianza es como exponer tu integridad a la expectativa de que otro hará algo bueno, pero puede que no. Eso es la confianza.

La confianza crea cooperación y la cooperación crea cultura. Esta es la fórmula de la cultura que un enfoque económico de la misma debe tener claro. El problema es que la confianza como proceso psicológico que crea cooperación y la cooperación (junto con las normas como reforzadoras de la cooperación) son difíciles de formalizar económicamente. En otras palabras, ¿cómo crear modelos de la cultura en la economía de la cultura que sean mensurables y que permitan hacer predicciones para que se puedan aplicar políticas culturales mucho más efectivas?

No es el propósito de este escrito decir qué tipo de modelo ha de ser aquel que mida cuantitativamente los factores que hay detrás de la emergencia de la cultura (cooperación, normas y confianza), como sí el de dar las pautas de guía para conocer adecuadamente ese modelo lo suficientemente válido y consistente para describir la cultura.

La cultura tiene un impacto en la economía que se produce principalmente por agentes o individuos que influyen a otros. Esta influencia se enciende como una mecha que se expande por toda una población 
de potenciales consumidores. Principalmente, lo que hace que alguien sea un "influenciador" es la confianza que otros, implícita o explícitamente, depositan en esa persona. Después, la naturaleza social de las personas y su inherente tendencia a cooperar y a establecer normas tácitas genera el caldo de cultivo para que una representación cultural, es decir, una idea, una preferencia o una creencia, se trasmita rápidamente como un virus que infecta y se propaga entre las personas. Esta descripción es cierta en términos generales, pero por qué se produce la confianza en un primer momento, desde el principio, entre dos personas es una cuestión que ha tenido ocupados a muchos investigadores durante años. Ahora parece que tenemos más pistas para poder apuntar a la causa de por qué se extiende la confianza.

De acuerdo con una larga tradición de modelización teórica que ha buscado las causas cognitivas próximas del comportamiento altruista basado en la confianza, la confianza se extiende entre las personas por la forma en la que la selección natural ha favorecido un modelo dual del procesamiento psicológico y conductual y que empíricamente se puede testar con las herramientas de la teoría de juegos. David Rand y colaboradores (Bear y Rand, 2016) han mostrado cómo la evolución y el aprendizaje selecciona agentes (personas) que son: 1) intuitivamente cooperadores (mediado por la confianza) pero que usan la deliberación para engañar o 2) intuitivamente engañadores que nunca deliberan. La confianza es un modo psicológico intuitivo de la motivación de las personas, o por lo menos de algunas, que se muestran cooperativos desde el primer momento y que solo cuando razonan y deliberan pueden actuar estratégicamente y engañar.

Por resumir, como somos por naturaleza sociales, somos también confiados por naturaleza.

Esta transmisión cultural basada en la confianza es epidemiológicamente hablando más rápida que una infección vírica. Sólo tienes que pensar en lo rápido que se trasmiten los rumores en un vecindario o en el lugar de trabajo. El efecto de propagación es proporcional al contacto o distancia de relación entre las personas (Christakis y Fowler, 2010). Para visualizar mejor cómo se produce la transmisión cultural se tienen que entender los papeles que juegan los distintos actores de cualquier esfera cultural. Los actores fundamentales son tradicionalmente: los creadores, los medios de distribución y los consumidores o usuarios. Con la irrupción de la tecnología digital y el gran acceso a la información y el conocimiento estos actores culturales se han transformado. ¿Por qué? Porque el consumidor o usuario ahora puede crear su propia actividad o práctica cultural gracias a la información y conocimiento disponible hoy en día, luego, por consiguiente, los creadores se expanden eliminando el binomio tradicional: creador-consumidor. Pero también los distribuidores se expanden eliminando otro binomio tradicional: distribuidor-consumidor. Ahora los consumidores pueden ser creadores y además distribuir gracias a la tecnología digital (Internet) su propio trabajo. El mapa del análisis económico de la cultura se ha transformado por completo.

Esta transformación produce aún más aspectos intangibles de la cultura difíciles de capturar cuantitativamente con una metodología económico-normativa (Gibson y Klocker, 2003).

\section{DISCUSIONES: LOS ASPECTOS INTANGIBLES DE LA CULTURA}

Se ha visto cómo la diversidad biológica y la diversidad cultural se pueden entender desde un mismo marco teórico: la evolución por selección natural de Darwin y Wallace y así conocer qué mecanismos están detrás tanto de los procesos biológicos como de los culturales. Esta analogía es válida y fructífera para entender cómo y por qué tenemos cultura.

Sabemos que la cooperación y las normas junto con la confianza son los mecanismos fundamentales de la evolución de la cultura. La confianza es el fenómeno que permite la cooperación y la cooperación -junto con las normas- permite la cultura. Partiendo del reconocimiento de los mecanismos que dan lugar a la cultura se puede intentar modelizar cuantitativamente la cultura. Pero aún así, no se puede ignorar que surgen aspectos intangibles de la cultura.

Es un fallo muy común por parte del discurso económico tradicional seguir creyendo que la cultura es un producto que se puede capturar con un valor de utilidad y asignar por tanto un precio de intercambio. Cierto es que al menos para la cultura material sí se puede, pero el componente simbólico de las distintas conceptualizaciones de cultura dota de una polivalencia a lo "cultural" difícilmente mensurable por los modelos económicos. La tecnología digital y las aspiraciones de la gente a que la cultura sea libre y gratuita ha cambiado las reglas de juego. Es difícil mantener un modelo basado en una tecnología de hace siglos con la actual tecnología digital y las nuevas preferencias sociales.

También se ha visto una transformación de los agentes culturales tradicionales: el consumidor puede 
ser creador y distribuidor de cultura al mismo tiempo (Toffler, 1984). Esto ha existido desde la producción artesanal y flexible pero las tecnologías de la información y de la comunicación, incluidas otras tecnologías mecánicas de producción, la cultura DIY (do it yourself), maker y hacker dan lugar a una economía colaborativa que ha provocado un punto de inflexión y un cambio de paradigma económico (Cohen y Sundararajan, 2015), donde el intercambio no se hace por profesionales, sino por pares, y la estructura de costes y precios puede ni existir o ser compensada por medios alternativos a un sistema monetario (v.g. bancos de tiempo, favores, altruismo puro...).

El marco teórico para entender la evolución de la cultura y los mecanismos responsables de su propagación son análogos a la evolución biológica. Este modelo de interpretación es válido. Pero las fuerzas transformadoras de la tecnología y el acceso más democrático al conocimiento han cambiado por completo el mapa de los agentes culturales y han amplificado o pronunciado aún más los aspectos intangibles de la cultura.

Por ejemplo, un libro, un concierto de música en directo, entre otros muchos fenómenos culturales, tenían un precio específico fijado por mecanismos de asignación de precios (el mercado) con la tecnología anterior. Ahora la cultura en el siglo XXI ha dejado de ser una cultura material de objetos o productos para convertirse en una cultura de experiencias con un profundo trasfondo social (Boswijk, Thijssen y Peelen, 2007), que hace que la cultura tenga un valor que no se puede expresar en estadísticas (Holden, 2004) y, a veces, ni siquiera se fije un precio. La economía de experiencias ha pasado desapercibida hasta ahora y ha sido la última fase de una transición económica de bienes a servicios y finalmente a experiencias. En esta economía de experiencias ya no es el bien material ni el servicio lo que cuenta, sino cómo te sientes.

Si verdaderamente la teoría económica quiere poder crear modelos mensurables de la cultura debe tener en cuenta que las experiencias subjetivas son difíciles de medir -no hay indicadores ni marcadores fiables a pesar de que las tecnologías de neuroimagen se están cada vez más utilizando como una ventana a la actividad de nuestra mente a la hora de consumir, comprar y decidir: Preston, Kringelbach y Knutson (2014)- sobre todo con una metodología de análisis desarrollada para modelizar intercambio de productos o bienes (objetos). La cultura son tradiciones de comportamientos y, por consiguiente, lo que se tendrá que cuantificar son hábitos culturales (y experiencias). Un ejemplo de hábito cultural es ir al cine. Pero la economía tradicional te diría que para medir el impacto o retorno económico del cine uno solo tiene que computar el número de asistentes a un estreno etc. Olvidándose del hecho de que la dimensión experiencial no solo se traduce en el número de personas que van a las salas de cine, es la implicación y compromiso de una persona con la experiencia de ver la película que puede llevar a esa persona no solo a ver la película en el cine, sino también a comentar en foros y redes sociales, visitar las localizaciones del filme en otro país (turismo), comprar una entrada para el concierto del artista que aparece en la banda sonora del filme, comprar merchandising del filme (camisetas, tazas...) etc. $Y$ todo esto no se puede prever o computar por el mero hecho de registrar la estadística de cuántos han acudido a las salas de cine (Holden, 2004; Throsby, 2003). Hay que crear modelos económicos que sean capaces de explicar cómo las experiencias son el nuevo activo de la economía cultural. Y mucho me temo que la modelización económica de la cultura ignora aspectos intangibles de los beneficios de la cultura.

La cultura actual es de experiencias porque el objeto o el producto ya no es lo más importante. Parte de esta desmaterialización, descorporalización del clásico objeto cultural tiene que ver con la irrupción de la tecnología digital. La tecnología digital permite copiar, almacenar, compartir eludiendo la fisicalidad de los objetos. Si recordamos, la "cultura material", los objetos creados de acuerdo a la trasmisión de información o las tradiciones de comportamientos, era una de las temáticas de la definición dada más arriba de cultura. Pero esta es una de las tres grandes temáticas. La industria de la música y la industria editorial (literatura) son dos ejemplos de artes que han experimentado un cambio de concepto de economía material a una economía de experiencias y la economía cultural debe tomar nota. Si la cultura actual es de experiencias, la economía actual debe ser de conocimiento o creatividad. Otra consecuencia de gran alcance, como se ha visto, es que los consumidores ya no son pasivos y ni siquiera son consumidores. Son creadores activos de cultura.

Como consecuencia de este nuevo estatus adquirido de las personas que pasan de ser consumidores a creadores, facilitado por la tecnología pero también por el acceso al conocimiento, incluso el tradicional modelo de derechos de autor, el mito del creador se queda obsoleto. Si todos somos creadores en potencia y la esencia de la cultura es la copia, trasmisión 
de información a través del tiempo, copiar y mezclar es el motor de la cultura. "Copiar" es la esencia de la cultura y copiar no es contrario a originalidad, dado que copiar facilita la creatividad, porque de las modificaciones que surgen de un acto inicial surge algo completamente nuevo. La cultura es trasmisión de información a través del aprendizaje social y el aprendizaje social es principalmente imitación, pero la imitación muchas veces no es fiel y de una simple variación que se acumula a través del tiempo surge algo completamente nuevo y original: la creatividad en acción. Nótese que este proceso cultural es similar al proceso de cambio en el mundo biológico.

Bien es cierto que de la modificación y copia no fidedigna de una idea se puede producir algo nuevo creativo, como algo nuevo degradado. El proceso de cambio cultural por acumulación de cambios trasmitidos entre personas es un proceso de creación, pero también de degradación. La múltiple copia de una idea cambia el argumento o su contenido, lo muta para deteriorarlo, y esto hace que se pueda saturar la cultura de copias degradadas y mediocres. Esto conlleva que solo los agentes cultos sepan distinguir entre copia con creación de una copia degradada.

Pero el mismo "espíritu" o filosofía de esta nueva economía de experiencias, colaborativa y de prosumers (palabra inglesa resultado de la suma de las palabras producers y consumers) hace que todos tendamos hacia el buen discernimiento de lo que es valioso culturalmente hablando. La educación y el conocimiento son, además de en cierta medida intangibles, el fundamento de esta nueva economía del siglo XXI.

La mezcla, la copia de otra copia, es lo que caracteriza a la cultura. Sin embargo, la legislación en materia cultural a nivel internacional criminaliza la copia (Lessig, 2008). El famoso copyright ahoga la creatividad cultural y supone una filosofía de la economía cultural cortoplacista y estéril (Lessig, 2002). Solo esta nueva economía cultural será realmente creativa si es libre y gratuita. Puede ser una expectativa o un pronunciamiento político, pero la cultura es un recurso de "comunes" en el sentido de Elinor Olstrom como recurso compartido que no se define por propiedad, sino por derechos de acceso. $Y$ todos tenemos derecho de acceso a la cultura y el conocimiento porque solo así crearemos nueva cultura y conocimiento en tanto y cuanto reconozcamos de dónde viene la idea, pero sabiendo que la idea no es poseída por nadie porque como hemos visto más arriba las ideas se mezclan e intercambian constantemente. Una verdadera economía de la cultura debe potenciar el derecho a mezclar y a copiar.
La ilusoria filosofía de los derechos de autor o propiedad intelectual por todos conocida, independientemente de la legislación nacional particular, como copyright trata los ítems (bienes y servicios) culturales como cualquier otro producto industrial. Pero esto es un error. Los ítems culturales son símbolos y estos son mucho más poderosos que cualquier iPhone, televisor o electrodoméstico. Como los ítems culturales son principalmente símbolos en la mente de las personas, medir el valor de la cultura con los métodos formales de la economía es una aventura de riesgo. Un euro (o póngase por caso cualquier otra divisa) invertido en cultura no es lo mismo que un euro invertido en otro activo. Mientras la inversión en ese otro activo desaparece con el agotamiento físico de ese bien, la inversión en cultura se perpetúa y se expande en la medida en que se propaga de una persona a otra.

Recapitulando, hay aspectos intangibles de la cultura imposibles de modelizar, por lo menos directamente, y con la irrupción de la tecnología y el acceso al conocimiento estos se ven amplificados. La deconstrucción del artefacto o producto cultural es el resultado de la acción de la tecnología y el acceso a gran escala del conocimiento que lleva a que los ítems culturales dejen de ser productos para convertirse en experiencias. Esto hace que crear un modelo de cultura desde la economía cultural sea complejo. Primero, porque no se concibe bien lo que la cultura es, y segundo, porque actualmente los ítems culturales son experiencias, no objetos. Estas ideas expuestas son controvertidas. También es posible que los distintos conceptos de cultura (creencias, estados mentales, valores o cultura material) se hayan entrecruzado en la argumentación y se requiera de un mayor rigor analítico y gran apoyo argumentativo, además de bibliográfico, que solo hemos querido señalar por razones de espacio. Pero esto es precisamente una muestra de la complejidad de la idea de cultura que impide por el momento una modelización económica comprehensiva de la misma. Pero el lector interesado puede dirigirse, como un comienzo para seguir profundizando en la complejidad de la economía cultural basada en la colaboración, el aprendizaje, el conocimiento y la investigación compartida a Throsby (2001) y Benkler (2007).

Con este escrito se ha intentado poder entender mejor qué es cultura en la economía de la cultura. Se ha hecho un breve apunte de la historia de la economía cultural y sobre la base de una analogía con el mundo biológico entendida desde el marco teórico del darwinismo se ha acotado el campo semántico de 
la noción de cultura. Se ha comentado la dificultad de medir, y por tanto dar valor, a la cultura teniendo en cuenta que hay aspectos intangibles de la cultura que se ven amplificados por la irrupción de la tecnología y el gran acceso al conocimiento hoy en día. El cómo de la transformación de los ítems culturales de objetos a experiencias, lo dejamos para futuras investigaciones.

\section{AGRADECIMIENTOS}

Agradezco el patrocinio del Gobierno Vasco para desarrollar una beca posdoctoral de investigación en el Uehiro Centre for Practical Ethics de la Universidad de Oxford y a esta última institución su cálida acogida.
Este trabajo se ha realizado en el marco de los proyectos de investigación KONTUZ!: Responsabilidad causal de la comisión por omisión: Una dilucidación ético-jurídica de los problemas de la inacción indebida (MINECO FFI2014-53926-R), La constitución del sujeto en la interacción social: identidad, normas y sentido de la acción desde la perspectiva de la filosofía de la acción, la epistemología y la filosofía experimental (FFI2015-67569-C2-2-P) y Artificial Intelligence and Biotechnology of Moral Enhancement. Ethical Aspects (FFI2016-79000-P). Agradezco también a los revisores anónimos sus sugerencias y comentarios para mejorar este escrito.

\section{NOTAS}

1 Agradezco a un revisor anónimo señalarme esta posibilidad.

2 Existe una disputa hermenéutica sobre la obra de Adam Smith (das Adam Smith problem) sobre si la visión de la motivación humana de Adam Smith reflejada en The Theory of Moral Sentiments es coherente o contradice la visión de la motivación humana expresada en The Wealth of Nations. Para muchos lo que se dice en esta última obra contradice lo que se dice en The Theory of Moral Sentiments. Pero quienes han interpretado a Adam Smith como el paladín de una economía de mercado libre sin escrúpulos morales ( $y$ hasta legales en forma de regulación) se equivocan intencionadamente o por ignorancia tal y como los editores del Glasgow Edition of the Works and Correspondence of Adam Smith sostienen.

\section{BIBLIOGRAFÍA}

Axelrod, R. y Hamilton, W. (1981). The evolution of cooperation. Science, 211, pp. 1390-1396. https://doi.org/10.1126/science.7466396

Baumol, W. y Bowen, W. (1965). On the Performing Arts: The Anatomy of their Economic Problems. The American Economic Review, 55, 1/2, pp. 495-502.

Baumol, W. y Bowen, W. (1966). Performing Arts. The Economic Dilemma. A Study of Problems Common to Theater, Opera, Music and Dance. New York: The MIT Press.

Bear, A. y Rand, D. (2016). Intuition, deliberation, and the evolution of cooperation. Proceedings of the National Academy of the United States of America. 113, 4, pp. 936-941. https://doi.org/10.1073/pnas.1517780113

Benkler, Y. (2007). The Wealth of Networks: How Social Production Transforms Markets and Freedom. New Haven: Yale University Press.

Boswijk, A. Thijssen, T. y Peelen, E. (2007). The Experience Economy: A New Perspective. Amsterdam: Pearson.
Christakis, N. y Fowler, J. (2010). Connected: The Surprising Power of Our Social Networks and How They Shape Our Lives. New York. Little Brown and Company.

Cohen, M. y Sundararajan, A. (2015). SelfRegulation and Innovation in the Peerto-Peer Sharing Economy. Dialogue. The University of Chicago Law Review, 82, pp. 116-133. Disponible en http://chicagounbound.uchicago.edu/uclrev_online/vol82/iss1/8

Corgnet, B., Espín, A. M., Hernán González, R., Kujal, P. y Rassenti, S. (2016). To Trust, or Not to Trust: Cognitive Reflection in Trust Games. Journal of Behavioral and Experimental Economics, 64, pp. 20-27. https://doi.org/10.1016/j. socec.2015.09.008

Gibson, N. y Klocker, N. (2003). Cultural industries and cultural policy: a critique of recent discourses in regional economic development. En Gao, J., Le Heron, R. and Logie, J. (eds). Windows on a changing world. Proceedings of the $22^{\text {nd }}$ New Zealand Geographical Society

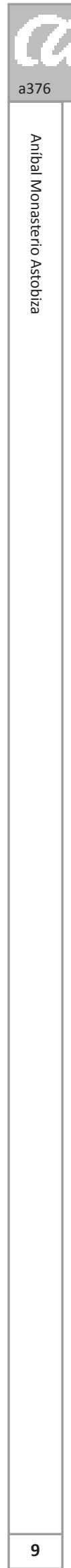

Conference. Auckland: New Zealand Geographical Society, pp. 131-135.

Hardin, G. (1968). The tragedy of the commons. Science. 162, pp. 1243-1248. https://doi. org/10.1126/science.162.3859.1243

Holden, J. (2004). The value of culture cannot be expressed only with statistics. Audience numbers give us a poor picture of how culture enriches us. London: Demos. [En línea]. Disponible en http:// www.demos.co.uk/files/CapturingCulturalValue.pdf

King-Casas, B., Tomlin, D., Anen, C. Camerer, C. F., Quartz, S. R. y Read Montague, P. (2005). Getting to Know You: Reputation and Trust in a Two-Person Economic Exchange. Science, 308, pp. 78-83. https:// doi.org/10.1126/science.1108062

Kroeber, A. y Kluckohn, C. (1952). Culture. A Critical Review of Concepts and Definitons. Papers of the Peabody Museum of American Archaeology and Ethnology. Cambridge Mass: Harvard University Press. 
Laland, K. (2017). Darwin's Unfinished Symphony: How Culture Made the Human Mind. Princeton: Princeton University Press. https://doi.org/10.1515/9781400884872

Lessig, L. (2002). The Future of Ideas: The Fate of the Commons in a Connected World. New York. Vintage

Lessig, L. (2008). Remix: Making Art and Comerce Thrive in The Hybrid Economy. New York: Penguin Press. https://doi. org/10.5040/9781849662505

Moggridge, D. (2005). Keynes, the Arts and the State. History of Political Economy, 37, 3, pp. 535-555. https://doi. org/10.1215/00182702-37-3-535

Odling-Smee, F., Laland, K. y Feldman, M (2003). Niche Construction: The Ne- glected Process in Evolution. Princeton: Princepton University Press.

Preston, S., Kringelbach, M. y Knutson, B. (2014). Introduction: Toward an Interdisciplinary Science of Consumption. En Preston, S., Kringelbach, M. y Knutson, B. (eds). The Interdisciplinary Science of Consumption. Cambridge Mass: The MIT Press. https://doi.org/10.7551/ mitpress/9780262027670.001.0001

Rousseau, D. M., Sitkin, S. B., Burt, R. S. y Camerer, C. (1998). Not so different after all: A cross-discipline view of trust. Academy of Management Review, 23, 3, pp. 393-404. https://doi.org/10.5465/ AMR.1998.926617

Throsby, D. (2001). Economía y Cultura. Madrid: Akal.
Throsby, D. (2003). Determining the value of cultural goods: How much (or how little) does contingent valuation tell us? Journal of Cultural Economics, 27, 3-4, pp. 275-285.

Toffler, A. (1984). The Third Wave. New York: Bantam.

Veblen, T. (1899/2001). The Theory of the Leisure Class: An Economic Study of Institutions. University of Virginia Library.

Wilson, D. S. (2013). Human Cultures Are Primarily Adaptive at the Group Level (with comment). Cliodynamics: The Journal of Theoretical and Mathematical History, 4, pp. 102-138. 